\title{
O “BYPASS" GÁSTRICO POR MINILAPAROTOMIA NA ERA DA CIRURGIA VIDEOLAPAROSCÓPICA
}

\author{
PERFORMING OPEN GASTRIC BYPASS BY MINILAPAROTOMY IN THE \\ VIDEOLAPAROSCOPIC ERA
}

Antonio Cláudio Jamel Coelho

Nos últimos anos, a obesidade se tornou uma epidemia em todos os segmentos da sociedade, não poupando nem mesmo a população de renda mais baixa. Este fato motivou a atenção de várias especialidades médicas, na busca de uma solução para este grave problema de saúde pública. É fato que até o presente momento, em que pese a intensa busca por novas drogas, o tratamento cirúrgico tem se mostrado o único tratamento eficaz em longo prazo.

$\mathrm{O}$ acúmulo da experiência com esta modalidade de tratamento, contribuiu para o entendimento das alterações neuroendócrinas resultantes das modificações anatômicas gastrintestinais promovidas pelo ato operatório, elucidando os mecanismos que explicam a resolução das graves comorbidades que afetam grande parte destes pacientes .

Paralelamente, a cirurgia laparoscópica, também conhecida como cirurgia minimamente invasiva, se desenvolveu no mesmo ritmo da evolução tecnológica, o que permitiu a manufatura de um grande número de dispositivos, que simplificaram algumas importantes fases da maioria das operações.

Em 1994, Wittgrove \& Clark $^{1}$ publicaram a primeira série de operações de "bypass" gástrico por vídeolaparoscopia, chamando a atenção da comunidade médica para esta nova modalidade de tratamento cirúrgico. Em sequiência, alguns grupos de cirurgiões Norte-Americanos, devidamente monitorados pelos órgãos de regulação, foram referenciados para a execução destas operações por vídeolaparoscopia, permitindo assim, que pequenos grupos acumulassem grande experiência. Devido ao número expressivo de pacientes referenciados, a chamada "curva de aprendizado" do método restou em aceitável número de complicações, conforme se demonstra na metanálise publicada por Nguyen ${ }^{2}$ e colaboradores em 2003.

Em nosso meio, a partir desta experiência inicial Norte-Americana, alguns grupos iniciaram a experiência da técnica vídeolaparoscópica sem um sistema hierarquizado, o que impediu o acúmulo de um número expressivo de pacientes por equipe, devido principalmente, a resistência das empresas de seguro saúde em liberar a realização destes procedimentos por esta via. Além do mais, a alta complexidade técnica do bypass por vídeolaparoscopia aliado ao cerceamento de acesso aos dispositivos de alto custo que a facilitam, fez com que muitos cirurgiões com experiência em cirurgia vídeolaparoscópica, se afastassem da cirurgia bariátrica, após breve experiência inicial.

Um outro dado de importância, é que o SUS até o presente momento, não prevê o pagamento de grampeadores laparoscópicos, inviabilizando a realização deste procedimento por videolaparoscopia em pacientes sem assistência suplementar de saúde. Ressalte-se que a maior parte dos obesos com indicação cirúrgica, não tem qualquer assistência suplementar de saúde.

Ao examinarmos a literatura médica, veremos que os resultados em termos de perda do excesso de peso entre as duas vias de acesso são iguais , restando a principal diferença nas complicações relativas ao ferimento cirúrgico, tais como: como hérnias incisionais, seromas e abcessos. Entretanto, também é certo, que existe uma relação direta entre o comprimento da incisão e estas complicações.

Tradicionalmente, a cirurgia bariátrica pela via convencional, é realizada com incisões xifo-umbilicais e subcostais bilaterais, este fato ocorre em função das dificuldades técnicas impostas pela acentuada obesidade. Na tentativa de diminuir as complicações de ferimento, fomos desenvolvendo progressivamente sistematização técnica, que foi concebida inicialmente, pelo Prof. Daoud Nasser da Universidade Estadual de Maringá.

Recentemente, durante a II Jornada da Rede Labs D’Or, apresentamos nossa casuística de 109 pacientes, submetidos à gastroplastia com bypass por minilaparotomia com incidência de 1,4\% de hérnia incisional em seguimento médio de 2 anos. É certo que um seguimento maior, revelará um aumento desta incidência, entretanto, os dados da literatura revelam taxas de hérnia incisional pela técnica aberta que variam entre 6 e $25 \%$ neste mesmo intervalo de seguimento ${ }^{3}$.

A incidência menor das hérnias incisionais, pode ser explicada pela lei de LaPlace, por esta lei, a resistência à pressão, é inversamente proporcional ao diâmetro. As mini-incisões se localizam exatamente na região sujeita à menor pressão intra-abdominal, que é o terço superior de uma incisão mediana.

Alguns fatores são adversos para a realização de incisões entre 7 e $10 \mathrm{~cm}$ de extensão, notadamente o aumento do lobo esquerdo do fígado por esteatose, a obesidade intraabdominal acentuada, além de mesentério curto .Ocorre que estes mesmos fatores são determinantes também para a con-

Membro Titular do Colégio Brasileiro de Cirurgiões; Membro Titular da Sociedade Brasileira de Cirurgia Bariátrica; Membro Titular da Sociedade Brasileira de Cirurgia Videolaparoscópica; Professor da Disciplina de Clínica Cirúrgica da Escola Médica do Rio de Janeiro-Universidade Gama Filho; Cirurgião do Hospital Barra D’Or. 
versão do acesso vídeolaparoscópico em laparotomia.Um outro aspecto importante, é a necessidade de dois auxiliares em campo operatório, o que pode ser um obstáculo em equipes de cidades menores, onde existe dificuldade de composição das mesmas.

Ocorre que na via laparoscópica, também são necessários dois auxiliares em campo, salvo com o uso de braço robótico para a câmera, que em função de seu alto custo, inviabiliza sua utilização pela maioria dos cirurgiões brasileiros.

O movimento em direção as operações pelo chamado acesso minimamente invasivo em toda a prática médica já está consolidado. Recentemente uma nova e atraente via de acesso chamada N.O.T.E.S., que é o acrônimo de cirurgia endoscópica por orifícios naturais na língua inglesa, desencadeou uma nova corrida pelo desenvolvimento de novos dispositivos e, por conseguinte um aumento de custos, que provavelmente será um novo obstáculo ao desenvolvimento desta via de acesso em nosso meio, já que a totalidade dos centros de desenvolvimento destas tecnologias, não está em território nacional.

Até que se encontrem mecanismos de redução destes custos e, em nossa opinião um mecanismo rápido de resolução, está no subsídio governamental via renúncia fiscal para estes dispositivos de alta tecnologia, o acesso convencional na cirurgia bariátrica deverá ser predominante, já que no caso em questão, os benefícios oferecidos aos pacientes na resolução de suas comorbidades e na melhora radical de sua própria condição física, tornam a via de acesso secundária.

A mini-laparotomia é um componente importante, na redução das complicações de ferimento operatório, principal desvantagem da cirurgia convencional no obeso mórbido.

\section{REFERENCIAS}

1. Wittgrove, AC ; Clark,GW - "Laparoscopic gastric bypass, a preliminary report of 5 cases " Obes Surg. 1994 Nov;4(4):353357

2. Podnos, YD ; Jimenez,JC ;Wilson ,SE; Stevens, CM ; Nguyen, NT - " Complications after laparoscopic gastric bypass- a review of 3464 cases "Arch Surg. 2003 Sep;138(9):957-61. Review

3. Capella, RF ; Iannace VA; Capella,JF," Reducing the incidence of incisional hernis during open gastric bypass surgery " Obes Surg. 2007 Apr;17(4):438-44. 